In all the cases in the preceding table where the canal and rings were of largely increased dimensions, Rothmund's instrument was applied, in order to combat the anatomical changes of the parts by the aid of the side-pieces. In most of the others, Wützer's was made use of.

CASE I, aged 38, is altogether a remarkable one. The instrument was removed on the fourth day, in consequence of some little terıderness and sickness, which soon subsided. The cylinder had not been smeared with the unguentum lyttæ. No bandage was applied, the puncture being dressed with simple ointment, and merely a support being used for the testicles. There was free suppuration about the seat of puncture, and a good deal of ulcerative irritation about the entrance to the invaginated scrotum. There was no evidence, during the three weeks that this patient was confined to his bed, of the plug having slipped down into its place again.

The following is his condition six months from the time of the operation:- No protrusion of intestine through the internal ring. No trace of plug to be felt in the canal. Rugæ of scrotum, on the side operated on, natural, save a slight redness in one spot. The internal ring itself can be distinctly localised, and is felt to be contracted and thickened.

I submitted this man to the examination of the members of the Birmingham Branch of the Association, at their meeting in April last. A very numerous assemblage of surgeons manipulated the rings under the intluence of the patient's cough, which had never left him. I heard no opinion expressed that did not affirm my own, as to the ring being effectually closed against protrusion, and likewise that the invaginated scrotum had subsided to its former position.

CASE II, aged 37 , had one of the largest and most unmanageable ruptures I ever felt. All the parts were flabby, and he had an incessant cough. He had been ruptured for eighteen years, and for the last ejght had not been able to wear a truss. The external ring communicated almost immediately with the abdominal cavity. Despite these drawbacks, the operation enabled him to wear a truss for the first time for eight years, and to keep his rupture effectually in place.

In Case Iv, aged 29, the plug remained firm, but the bowel descended slightly behind at the end of a fortnight. This patient suffered from obstinate stricture, frequently complicated by retention of urine; this latter condition being aggravated during the wearing of the instrument.

In CASE $\mathrm{v}$, aged 42 , on the seventh day of wearing the instrument, an erysipelatous redness of distinct character, and accompanied by the ordinary constitutional disturbance, spread about the abdominal wall from the seat of puncture. The cylinder was at once removed, and the symptoms soon subsided. The man had a bad habit of body, and had lived fieely. There was no undue pressure exercised, and not more than the ordinary slough at the seat of puncture.

In Case xI, aged 7, the boy had a large scrotal rupture, observed at birth. The canal was shortened and much straightened. In removing the cylinder, on the seventh day, with ordinary gentleness, the plug of scrotum descended with it. There was free suppuration about the puncture, and a good deal of adjacent inflammation in the canal, so that the bowel did not protrude for some few days; but the internal ring was a very large one for so young a subject, or I might have hoped for the curative contraction and adhesion to have been set up, as in Case I. This ended, however, in the bowel coming down into the scrotum, as before.

Of the preceding instances, then, five have resulted, at present, in the closure of the inguinal canal against all protrusion of the intestine. Five have so lessened the width of the passage that the amount of bowel escaping has been diminished considerably; so that a truss, in some instances for the first time for many years, could be worn. One failed altogether, from the slipping down again of the plug of scrotum, on the removal of the instrument.

In the cases in which the bowel came down, the plng of scrotum yet remaining attached, the escape invariably occurred behind its position, at the anterior margin of the ring.

One case alone evidenced during the treatment some alarming symptoms: these were, however, accounted for by the advent of a slight attack of erysipelas.

The sloughs, which generally formed at the point of exit of the needle, were limited in size, and soon healed; whilst the suppuration in the canal of the plug, and in the inguinal one also, were throughout of the most manageable character.

Taking into consideration, therefore, the varieties of reiucible inguinal ruptures in especial regard to the utility of this operation, my opinion is, that we may fairly estimate their prospects of cure, improvement, or absolute failure, according to certain characteristics which place them in three divisions.

In the first, we number the small, firm, well defined internal ring in the narrow canal, not much shortened. The more muscular and youthful the sulject, the better.

In the second, a large ring, relaxed, with a broad short canal and surrounding flabby textures, as in so many old ruptures.

In the third are the protrusions of persons in very advanced life, the features of which are marked by vast size, by long con. tinuance, and by their constant enemy, the bronchial cough.

\section{INFLUENCE OF VITALITY UPON SECRETION: REPLY TO MR. SPENDER.}

By T. InMan, M.D., Liverpool.

I An afraid that the explanation offered by $\mathrm{Mr}$. Spender, of the phenomena to which I called attention in my communication of April 30th, is inadequate to satisfy the circumstances of the case. It assumes that there are two forms of secretion, active and passive; and it goes on to define the latter as "an almost entirely physical act, independent of nerve power," "scarcely deserving the name of a vital function at all." Again, in illustration, he speaks of "the diminished tone of the capillary walls allowing the water of the blood to permeate them," "the haste with which the water filters through the Malpighian tufts ".....the act is less a vital than a physical one," and he says, "where nerve-force is lessened, the secretional product must be lessened in an equal ratio."

In few words, Mr. Spender seems to think that where there is increased secretion with diminished power, we have the usual amount of solid matter, plus a considerable quantity of water, and nothing more.

This simple way of putting the matter suffices for a refutation of one idea promulgated; but the subject is too interesting to be thus summarily dealt with. I propose to consider it, therefore, more at length.

First, as to "nerve-power." What do we really know of its influence on secretion? We know that under certain mental emotions, certain secretions are increased or diminished; that the effects of dividing nerves, going to certain organs, is un certain, and there our real knowledge ceases. Per contra, we see secretion going on in plants, where there is no nervous system. The same may be said of the "actiniæ", in which no such system can be demonstrated; and the same of transparent larvæ, whose every nerve we can trace. We can see in the transparent part of the kidney of the triton, that the renal tubes and Malpighian bodies and capsules are unaccompanied by nerves-and yet secretion goes on. We cannot demonstrate the presence of nerves in the membrane lining the Haversian canal, or in the lacunæ of bone or cartilage. No nerve can be demonstrated in the membrane covering articular cartilage, nor does the anatomist pretend that there is a nerve for every small lobule of the liver, or for every individual air-cell in the lung. The peritoneum, pleura, and pericardium, are not universally covered with nerves, and I do not think that any microscopist has discovered an abundant supply for the arachnoid-yet all these parts secrete their own peculiar fluid. If, then, secretion will go on without nerve-power being demonstrably present, we must not appeal to that force to get us out of our difficulties; this is, simply to explain something, of which we lnow little, by referring it to something of which we kuow less-a very common error nevertheless.

Secondly. Is the increased secretion of which we have spoken simply a physical act? If so, we should have its analogue in the dead body; we should find in every corpse the evidence of gonorrhœa and perspiration, leucorrhœe and dropsy; but we have no such phenomena. Perspiration does not break out in a limb just about to mortify, or where it is already dead from ligature of its principal artery; nor does it occur in death by all diseases. Bronchitis does not always attend old age, or dropsy invariably wait upon debility. If these increased secretions are due to physical causes chiefly, they would occur equally in all cases of extreme astbenia.

Thirdly. Is the so-called "passive secretion" simply the natural one diluted with fluid? In some instances, as in dia. betes insipidus, it may be so; but, as a rule, we find that the quantity of solids discharged is excessive, and the quality is changed. Thus, in health, the mucous membrane of the nose of the bronchi, and of the bladder, secrete only a very small 
quantity of mucus ; but when they are debilitated by struma, age, or accident, they secrete enormous quantities, not of mucus, but of pus, and no one can demonstrate that the latter is only a dilution of the former.

But there is yet another point, of great practical importance, bearing on this subject. There is scarcely any disease attended with more intense debility than diphtheria; yet it is characterised by an immensely congested condition of the throat, etc.; and a very abundant dense secretion from the mucous membrane, and, under the influence of strong general and local stimulation, the secretion is thinned in consistence and reduced in amount.

The bearing of this upon the common "cynanche trachealis" must be at once apparent, and it ought to be a question how far the density of the secretion of false membrane in that disease may not have frequently been promoted and increased by the state of debility into which the patient is too often reduced by antiphlogistic treatment. I can only say that after a diligent hunt after cases, $I$ have found that those in which death has taken place under twenty-four hours, and where the formation of false membrane has been most dense and abundant, have been those where the patients have been copiously bled at the outset, and where the vitality is consequently very low.

We cannot refer the false membrane formed in diphthe. ria, or the reduction in density and quality which follows in that disease, from the use of local and general stimulants, to any physical agency whatever. Consequently, we must reject the notion that excessive secretion, with debility, has chiefly a physical canse.

But there is still another way in which Mr. Spender's explanation must be cxamined; viz., the influence the doctrine would have on practice. If excessive perspiration in phthisis be simply the exudation of an unusual quantity of the aqueous part of the blood, and a physical process into which vitality enters little, it ousht not to weaken the patient so long as he is able to supply the blood with the water which has been drained away. If infantile diarrhea be nothing more than a copious loss of fluid from weakened blood-vessels, it might be easily compensated for by an abundant use of aqueous drinks. And if, in diabetes insipidus, the only thing to be noticed is that "the haste with which the water filters through the Malpighian tufts leaves scarcely any time for it to be impreanated with the contents of the epithelial cells that line the uriniferous tubes," there will be no difficulty in keeping the patient "up to the mark" by making him drink as much water as he expends.

We know that such physical illeas are unprofitable in the main to the living man.

Mr. Spender, however, guards himself by saying that what he calls passive secretion is almost cntirely a physical act. These two words, to a great extent, show that our ideas are not directly opposed. As a matter of philology, I object to an act being spoken of as passive. As a matter of fact, I believe that all living matter comes under the laws of inorganic force, in direct proportion to the diminution of organic power. In that we agree.

My wish is to show that there is a condition of the body in termediate between perfect health and absolute death, which has not yet been sufficiently studied. The living body has certain powers and tendencies, which we speak of as organic or vital. The dead body has certain others, which we know as physical and inorganic. Of the mutual reaction of these opposing forces, when the forner is weakened, we really know little.

Circumstances have induced me lately to investigate them as closely as I can. The results attained are of extreme interest. I will not enter into them, however; but sum up the question before us in the worls of one of the most original thinkers of the day, Mr. Lewes. "What is the organic process on which this excess of secretion (in debility) depends? Vitality is only a general phrase. I cannot help thinking that the old idea is correct which says that increased secretion results from an increased activity of the secreting organ, increased special power, though caused, perhaps, by an organic disturbance which is coincident with diminished general power. The latter point being brought to light, the attention should be directed to the mod:us operandi."

I doubt myself whether we can consider that "increased snecial power" can be present in an organ secreting over abundantly, when such secretion is diminished by local stimulants as much as by general ones; but the problem is so fairly put that I will leave it as it is, feeling sure that if it be worked out fairly, it will eventuate in a vast improvement, both in patho. logy and practice.

\section{Clinital aperture}

A S THEN I C P P E M O I A,

DELTVERED TO

THE STUDENTS OF THE BIRMINGHAM GENERAL HOSPITAL.

By J. Russelt, M.D., one of the Physicians to the Hospital, and Lecturer on Pathology at Sydenham College.

Gentlenen,-There are at present in the Hospital tiro cases of acute rheumatism, which we have watched with considerable interest, on account of their presenting the serious complication of pneumonia of a low type affecting both lungs. From whatever circumstances it arises, it is an unquestionable fact, that the low forms of preumonia are far more common-in towns, at least-than those of a more sthenic character. Asthenic pneumonia, or typhoid pneumonia, as it is often called, by an unfortunate misapplication of terms, is a disease of by no means infrequent occurrence, often presenting itself as a complication of some preexisting disease, sometimes existing as a simple primary affection; under either condition, it possesses some peculiar features which merit your especial attention; and which I propose to make the subject of the present lecture.

The descriptions of disease which are given in systematic treatises and lectures are generally derived from certain typical forms, and it is necessary that this should be so ; but in applying the knowledge you have thus gained to clinical observation, you will be perpetually reminded that the proportion of cases which realise, in all respects, the descriptions you have read, is very small indeed; and you must be prepared to encounter many and wide deviations from the model form which has been placed before you. Such is eminently the case with inflamma tion of the lungs. Perhaps no malady is attended with less uncertainty in its diagnosis than a genuine case of simple sthenic pneumonia : on the contrary, there are few more insidious than the same disease in its asthenic form. Where asthenic pneumonia exists as a secondary affection, it is not infrequently so entirely destitute of special symptoms that its presence may be entirely overlooked; and were it not for our knowledge of the circumstances under which its occurrence may be expected, our attention might never be directed to the chest. In each of the cases at present under our consideration, there was no reason whatever to suspect the existence of the disease prior to the physical examination of the lungs. In feeble or unhealthy subjects, again, pneumonia, although it be the sole or primary affection, is often deprived of some of its most characteristic signs.

When pneumonia occurs as a secondary affection, it is spoken of as intercurrent. It is a more or less frequent complication of many diseases, which are produced by the presence of a poison in the blood; thus it is met with in the course of typhus fever, in erysipelas and surgical fever, in scarlatina, measles, and influenza, in remittent and yellow fever, and, as we have also found, in acute rheumatism. It appears not improbable that it may sometimes exist as the direct consequence of a morbid poison where no other indications are afforded of the presence of that poison in the blood, just as in every epidemic of scarlet fever we find isolated cases in which the characteristic affection of the throat is the only symptom of the disease which is present. Thus, whilst erysipelas is prevailing in the wards of a hospital, and the subjects of wounds or of operations are liable to be seized with that malady, instances every now and then occur of patients similarly circumstanced suffering from asthenic pneumonia, which we have every reason to refer to the poison of erysipelas, although the usual cutaneous inflammation be absent.

But the disease is also met with where we have no reason to suspect the existence of any specific poison in the blood; it may occur after exposure to cold, or to the operation of any ordinary cause of simple inflammation, in enfeebled individuals who have been exhausted by overwork, by anxiety, or by other depressing agencies, or who have lowered their health by intemperance, or by unhealthy habits of life. Such appear to be instances of ordinary inflammation, occurring in a debilitated constitution, which imparts to them their asthenic type. Yet, 